\title{
Synthesis of Novel Aromatic Core Zero Generation Dendrimers
}

\author{
Melinda-Emese Füstös, Tímea-Anita Sipos, Mircea V. Diudea, and Gabriel Katona* \\ Department of Chemistry, Faculty of Chemistry and Chemical Engineering, Babeș-Bolyai University, \\ Arany János 11, RO-400028, Cluj-Napoca, Romania

Abstract. Bromomethyl arenes used as polyfunctional core of dendrimers were derivatized with diethanolamine branches. The obtained compounds containing 4 or 6 hydroxyl terminal surface groups are highly water-soluble.

Keywords: dendrimer, bromomethyl arenes, diethanolamine

\section{INTRODUCTION}

The first dendrimer-like structure was presented in 1978 by Fritz Vögtle as a highly-branched macromolecule. ${ }^{1}$ Dendrimers are typically symmetric around the core, mono-dispersed molecules, having a very well defined size and delimited shape, respectively. The core is derivatized with branching molecules, containing functional groups, organized in generations. A subunit of the dendrimer is called a dendron. Dendrimers can be obtained by divergent (construction of the molecule is progressing from the core to the surface) or by convergent (starting from the end-groups and stepwise progressing inwards and lately attaching the dendron to the core) routes. ${ }^{2}$ The control over size, shape, and surface functionality makes dendrimers one of the "smartest" or customizable commercially nanotechnology products. ${ }^{3}$

Herein we report the synthesis of zero generation dendrimers using 1,4-bis(bromomethyl)benzene, 1,3,5tris(bromomethyl)benzene and 1,3,5-tris(bromomethyl)2,4,6-trimethylbenzene as the core. Derivatization was made with diethanolamine and leaded to highly polar compounds.

Diethanolamine (DEA) is known for its application in several fields: as surface-active agent in cosmetics, agricultural products or pharmaceuticals. ${ }^{4}$ Biological testing proved that DEA derivatives show antibacterial, antifungal, anticancer and antioxidant properties. ${ }^{5}$

In the synthesis of some metallodendrimers 1,4bis(bromomethyl)benzene has been used as a linking agent. ${ }^{6}$ Dendrimers constructed from 1,3,5-tris(bromomethyl)benzene core and derivatized with sodium tris(ethoxycarbonyl)methanide, 4-formylbenzoic acid, triethyl phosphine, 2-(2-pyridyl)benzimidazole, tosylate or N-tosylated aminoisophtalate diester ${ }^{7-11}$ had been reported. Literature data regarding the use of 1,3,5tris(bromomethyl)-2,4,6-trimethylbenzene as central unit is related mainly to metallodendrimer synthesis. ${ }^{12}$

Since diethanolamine possesses the properties of secondary amines and alcohols due to the presence of both amino and hydroxyl functional groups, it undergoes different reactions. DEA reacts with acyl chlorides, cellulose derivatives or acids. It is also a suitable precursor for the morpholine synthesis. ${ }^{12}$ Morpholine was first obtained by the dehydration of diethanolamine in the presence of sulfuric acid. Several methods have been tested in order to obtain the heterocyclic compound in higher yield. ${ }^{13}$ Morpholine derivatives have a large scale of applications: as sulfur dioxide absorbent, ${ }^{14}$ as catalyst, ${ }^{15,16}$ in biochemical applications, ${ }^{17,18}$ in different hydrogels preparation, ${ }^{19,20}$ in morpholine-based chemotherapeutic agent synthesis. $^{21-23}$

\section{EXPERIMENTAL}

\section{Materials and Methods}

The starting chemicals: 1,4-bis(bromomethyl)benzene, 1,3,5-tris-(bromomethyl)benzene, 1,3,5-tris(bromomethyl)-2,4,6-trimethylbenzene, anhydrous potassium carbonate and diethanolamine were purchased from Sigma-Aldrich. Acetonitrile, ethanol, diethyl ether and $48 \%$ aqueous hydrobromic acid were supplied from Merck. All chemicals and reagents were used as received.

\footnotetext{
* Author to whom correspondence should be addressed. (E-mail: gabik@chem.ubbcluj.ro)
} 
Thin layer chromatography (TLC) monitoring was carried out using Merck Kieselgel 60 F 254 sheets. Spots were visualized by the use of UV light at $254 \mathrm{~nm}$ and colored via treatment with $5 \%$ ethanolic phosphomolybdenic acid solution followed by heating. UVVisible absorbance spectra were obtained using an Agilent 8453 spectrophotometer. Electrospray ionization mass spectrometry (ESI-MS) was involved for product characterization, the spectra were recorded on Agilent / Technologies 6320 spectrometer at room temperature; ${ }^{1} \mathrm{H}$ and ${ }^{13} \mathrm{C}$ NMR spectra were recorded on Bruker spectrometers operating at 400 and $100 \mathrm{MHz}$ respectively at 600 and $150 \mathrm{MHz}$.

\section{Synthesis of Compounds 3a-c}

For the synthesis of the novel dendrimers $3 \mathrm{mmol}$ of the aromatic core $(\mathbf{1} \mathbf{a}-\mathbf{c})$ was dissolved in acetonitrile under continuous stirring at $40{ }^{\circ} \mathrm{C}$. Separately, diethanolamine $(6.3 \mathrm{mmol})$ was dissolved in acetonitrile and added to the reaction mixture. After homogenization, anhydrous potassium carbonate was added in excess in order to neutralize the formed hydrogen bromide. The resulted mixture was stirred for $24 \mathrm{~h}$ under reflux conditions. Completion of the reaction was monitored by TLC. Next, the mixture was allowed to reach room temperature. The unreacted potassium carbonate and the formed potassium bromide were separated by filtration. The filtrate was then evaporated using a rotary evaporator. The resulted products were purified by vacuum distillation. The obtained dendrimers were viscous, slightly yellowish liquids.

\section{Synthesis of Compounds $4 a$ and 5}

2,2',2", 2'"-[1,4-phenylenebis(methylenenitrilo)]tetraethanol $(1.6 \mathrm{mmol})$ was dissolved in aqueous hydrobromic acid, added in large excess under stirring. The resulted mixture was heated at $130{ }^{\circ} \mathrm{C}$ on a silicon oil bath. A Dean-Stark apparatus was attached to the flask and used for the continuous removing of the produced water in order to maintain the concentration of $\mathrm{HBr}$ in the reaction mixture. After the evacuation of water, the unreacted acid was removed by connecting the flask to vacuum. The resulted solid phase was dissolved in ethanol, active carbon was added and next filtered. The filtrate was evaporated on a rotary evaporator to half of its initial volume. Diethyl ether was added dropwise. The formed precipitate was filtered and dried overnight. The obtained morpholine derivative was a white solid.

The method described above was applied also for the synthesis of compound 5 using $9.5 \mathrm{mmol}$ of substrate 2. After the purification procedure a white crystalline product resulted.

\section{NMR Spectra}

3a. 2,2',2",2'"-[1,4-Phenylenebis(methylenenitrilo)]tetraethanol $\left(\mathrm{C}_{16} \mathrm{H}_{28} \mathrm{~N}_{2} \mathrm{O}_{4}\right)$

$0.81 \mathrm{~g}(87 \%) ;{ }^{1} \mathrm{H}$ NMR (600 MHz, $\left.\mathrm{D}_{2} \mathrm{O}, 293 \mathrm{~K}\right) \delta /$ ppm: 2.82 (t, 8H, -N- $\left.\mathrm{CH}_{2}-\right), 3.71$ (t, 8H, $\left.-\mathrm{CH}_{2}-\mathrm{O}-\right)$, $3.86\left(\mathrm{~s}, 4 \mathrm{H}\right.$, aryl- $\left.\mathrm{CH}_{2}-\right), 7.40(\mathrm{~s}, 4 \mathrm{H}$, aryl $) ;{ }^{13} \mathrm{C} \mathrm{NMR}$ (150 MHz, $\left.\mathrm{D}_{2} \mathrm{O}, 293 \mathrm{~K}\right) \delta /$ ppm: 54.74, 57.88, 62.49, 130.30, 135.45; MS $m / z: 313\left([\mathrm{M}+\mathrm{H}]^{+}, 100 \%\right)$.

3b. 2,2',2",2'"',2'"', $2^{\prime \prime \prime \prime \prime-}-[1,3,5$-Phenylenetris(methylenenitrilo)] hexaethanol $\left(\mathrm{C}_{21} \mathrm{H}_{39} \mathrm{~N}_{3} \mathrm{O}_{6}\right)$

$1.17 \mathrm{~g}(91 \%) ;{ }^{1} \mathrm{H}$ NMR (400 MHz, $\left.\mathrm{D}_{2} \mathrm{O}, 293 \mathrm{~K}\right) \delta /$ ppm: 2.68 (t, 12H, -N- $\left.\mathrm{CH}_{2}-\right), 3.65$ (t, 12H, $\left.-\mathrm{CH}_{2}-\mathrm{O}-\right)$, $3.70\left(\mathrm{~s}, 6 \mathrm{H}\right.$, aryl- $\left.\mathrm{CH}_{2}-\right), 7.25$ (s, 3H, aryl); ${ }^{13} \mathrm{C} \mathrm{NMR}$ $\left(100 \mathrm{MHz}, \mathrm{D}_{2} \mathrm{O}, 293 \mathrm{~K}\right) \delta / \mathrm{ppm}: 54.92,58.14,58.63$, 130.34, 137.67; MS $m / z$ : $430\left([\mathrm{M}+\mathrm{H}]^{+}, 100 \%\right)$.

3c. 2,2',2",2"', $2^{\prime \prime \prime \prime \prime, ~ 2 " ' " '-[2,4,6-T r i m e t h y l-1,3,5-p h e n y l e-~}$ netris(methylenenitrilo)] hexaethanol $\left(\mathrm{C}_{24} \mathrm{H}_{45} \mathrm{~N}_{3} \mathrm{O}_{6}\right)$ $1.25 \mathrm{~g}(89 \%) ;{ }^{1} \mathrm{H}$ NMR (400 MHz, $\left.\mathrm{CD}_{3} \mathrm{OD}, 293 \mathrm{~K}\right) \delta /$ ppm: $2.48\left(\mathrm{~s}, 9 \mathrm{H},-\mathrm{CH}_{3}\right), 2.70\left(\mathrm{t}, 6 \mathrm{H},-\mathrm{N}-\mathrm{CH}_{2}\right), 3.52(\mathrm{t}$, $\left.12 \mathrm{H},-\mathrm{CH}_{2}-\mathrm{O}-\right), 3.92\left(\mathrm{~s}, 6 \mathrm{H}\right.$, aryl- $\left.\mathrm{CH}_{2}-\right) ;{ }^{13} \mathrm{C} \mathrm{NMR}$ (100 MHz, $\left.\mathrm{CD}_{3} \mathrm{OD}, 293 \mathrm{~K}\right) \delta / \mathrm{ppm:} \mathrm{17.37,} \mathrm{56.70,}$ 60.20, 139.43; MS $m / z$ : $472\left([\mathrm{M}+\mathrm{H}]^{+}, 100 \%\right)$.

4a. 4,4'-[1,4-Phenylenebis(methylene)] dimorpholine $\left(\mathrm{C}_{16} \mathrm{H}_{24} \mathrm{~N}_{2} \mathrm{O}_{2}\right)$

$0.37 \mathrm{~g}(84 \%) ;{ }^{1} \mathrm{H}$ NMR (400 MHz, DMSO- $\left.d_{6}, 293 \mathrm{~K}\right) \delta$ / ppm: $3.14\left(\mathrm{t}, 8 \mathrm{H},-\mathrm{N}-\mathrm{CH}_{2}-\right), 3.78\left(\mathrm{~s}, 4 \mathrm{H}\right.$, aryl- $\left.\mathrm{CH}_{2}-\right)$, $4.43\left(\mathrm{t}, 8 \mathrm{H},-\mathrm{CH}_{2}-\mathrm{O}-\right), 7.62(\mathrm{~s}, 4 \mathrm{H}$, aryl $) ;{ }^{13} \mathrm{C} \mathrm{NMR}$ $\left(100 \mathrm{MHz}, \mathrm{DMSO}-d_{6}, 293 \mathrm{~K}\right) \delta / \mathrm{ppm}: 50.85,58.47$, 63.17, 130.61, 131.93; MS $m$ / z: $277\left([\mathrm{M}+\mathrm{H}]^{+}, 100 \%\right)$.

\section{RESULTS AND DISCUSSION}

Synthesis of the aromatic core $(\mathrm{G}[0])$ of dendrimers was accomplished according to Scheme 1.

For compound 3a we present a new method of synthesis while compounds $\mathbf{3 b}$ and $\mathbf{3 c}$ are newly synthesized. Since the surface functional groups are $-\mathrm{OH}$, the dendrimers are highly soluble in polar solvents.

We tested different solvents, as reaction media, and acetonitrile proved to be the suitable for this

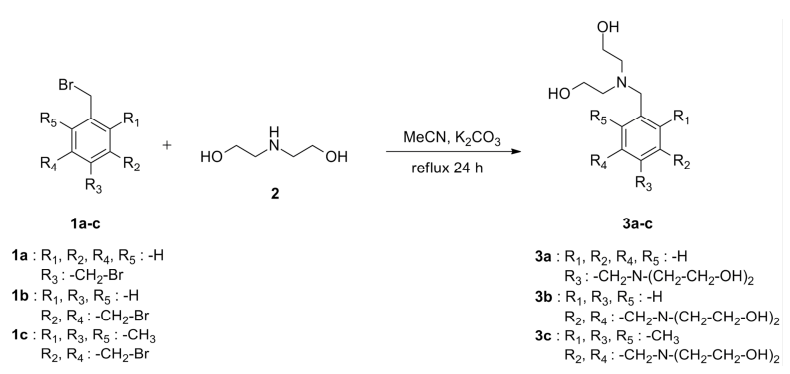

Scheme 1. Synthesis of dendrimers. 


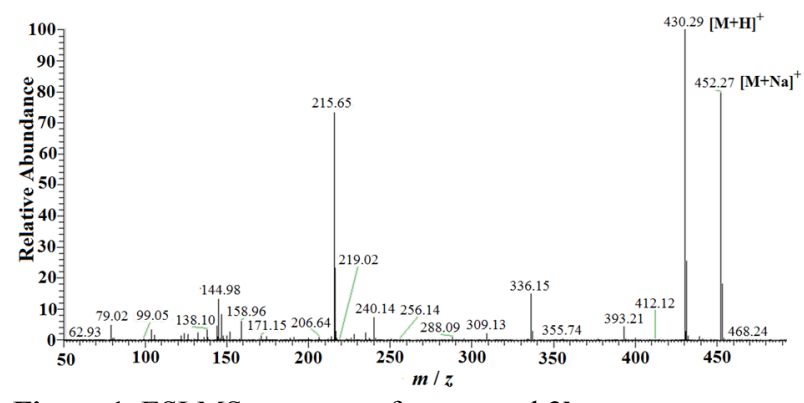

Figure 1. ESI-MS spectrum of compound $\mathbf{3 b}$.

purpose. Reactions were carried out also using triethylamine instead of potassium carbonate to remove the formed hydrogen bromide from the reaction mixture; unfortunately, we encountered difficulties in separation of the formed triethylammonium bromide, it being soluble in acetonitrile. For the purification of compounds 3a-c column chromatography was first used but the separation of unreacted DEA from the dendrimer was not successful; vacuum distillation made this possible.

\section{Mass Spectrometry}

The ESI technique, ${ }^{25}$ being useful in both low mass molecules and macromolecules characterization, was involved as characterization method. Methanolic solutions of the synthesized compounds containing $0.5 \mathrm{mg} \mathrm{mL} \mathrm{m}^{-1}$ substrate per sample were analyzed. Figure 1 illustrates the recorded mass spectrum of compound 3b. The peak at $m / z=430$ corresponds to $[\mathrm{M}+\mathrm{H}]^{+}$. Also the peak for $[\mathrm{M}+\mathrm{Na}]^{+}$is detectable at $m / z=452$.

In the mass spectrum of compound $\mathbf{3 c}$ (Figure 2) the peak for $[\mathrm{M}+\mathrm{H}]^{+}$appears at $472 \mathrm{~m} / \mathrm{z}$ value.

\section{NMR Spectroscopy}

All compounds were structurally characterized by nuclear magnetic resonance spectroscopy. In Figure 3 the ${ }^{1} \mathrm{H}-\mathrm{NMR}$ spectrum for compound $\mathbf{3 b}$ recorded in $\mathrm{CD}_{3} \mathrm{CN}$ is depicted. Comparing the signals with the ones appearing on the spectrum recorded in $\mathrm{D}_{2} \mathrm{O}$, a new signal is present at $3.14 \mathrm{ppm}$ assigned to the terminal

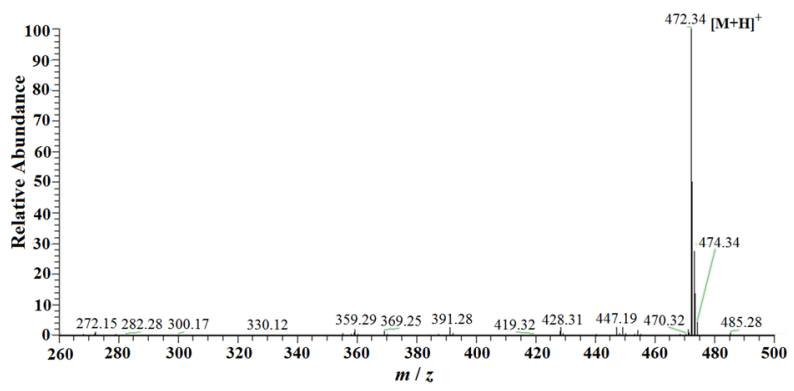

Figure 2. ESI-MS spectrum of compound $\mathbf{3 c}$.

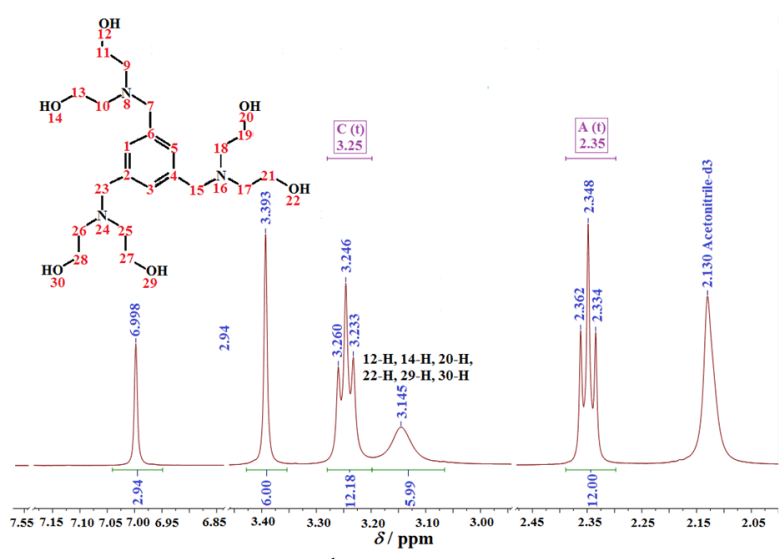

Figure 3. Fragment of the ${ }^{1} \mathrm{H}-\mathrm{NMR}$ spectrum of compound $\mathbf{3 b}$ [CD ${ }_{3} \mathrm{CN}, 298 \mathrm{~K}, 400 \mathrm{MHz}$.

$-\mathrm{OH}$ protons. Based on these findings in order to differentiate the methylene protons from the diethanolamine chains, the corresponding quaternary ammonium salt of the product was formed by adding $\mathrm{HCl}$ to compound $\mathbf{3 b}$.

The spectrum recorded in DMSO- $d_{6}$ (Figure 4) shows a broad multiplet of four peaks at $3.28 \mathrm{ppm}$, $3.26 \mathrm{ppm}, 3.22 \mathrm{ppm}$ and $3.20 \mathrm{ppm}$ assigned to the $\mathrm{H}-\mathrm{a}$, $\mathrm{H}-\mathrm{a}$ ' noted protons while another multiplet is detected, with four peaks at $3.79 \mathrm{ppm}, 3.79 \mathrm{ppm}, 3.78 \mathrm{ppm}$ and $3.77 \mathrm{ppm}$ assigned to protons noted by H-b, H-b'. This unexpected splitting of the signals suggests that the geminal $\mathrm{H}-\mathrm{a}, \mathrm{H}-\mathrm{a}$ ' and $\mathrm{H}-\mathrm{b}, \mathrm{H}-\mathrm{b}$ ' pairs are diastereotopic. In the aromatic zone, the splitting of the signal is also observed. A multiplet appears between 7.82-8.05 ppm, corresponding to the benzenic protons $(1-\mathrm{H}, 3-\mathrm{H}, 5-\mathrm{H})$.

Forasmuch the diethanolamine branch methylene protons are differenced and the aromatic protons are not

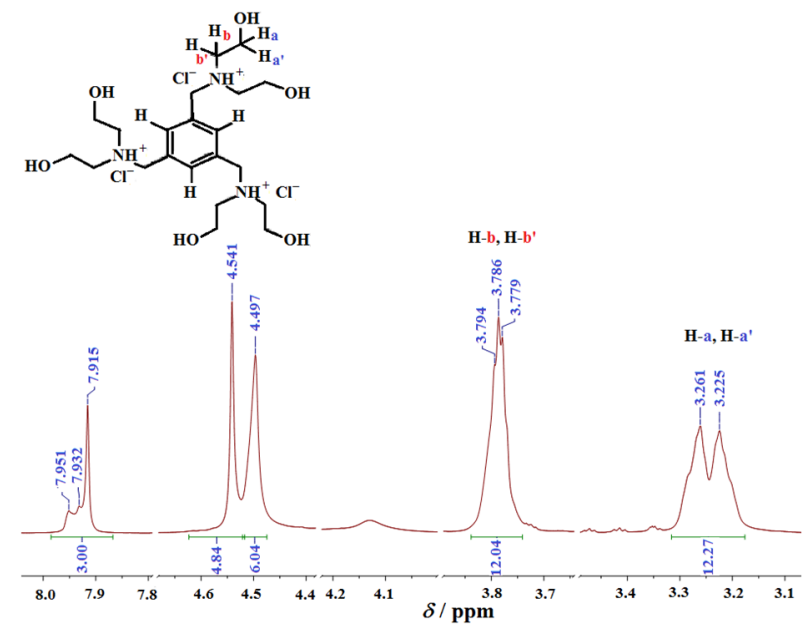

Figure 4. Fragment of ${ }^{1} \mathrm{H}-\mathrm{NMR}$ spectrum of the quaternary ammonium salt of compound 3b [DMSO-d $6,298 \mathrm{~K}$, $400 \mathrm{MHz}]$. 

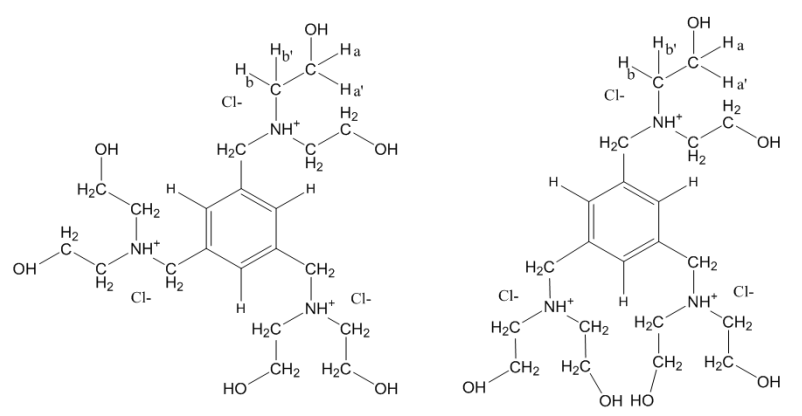

Figure 5. Suggested conformations for compound $\mathbf{3 b}$.

equivalent, one can conclude that compound $\mathbf{3 b}$ has two isomers. The suggested conformations are shown in Figure 5.

\section{UV Spectroscopy}

The aqueous solution of the considered compounds shows no UV absorption changes in the range of $200-400 \mathrm{~nm}$.

In order to grow the dendrimer by one generation, a new derivatization step with diethanolamine is required. For this purpose, the terminal hydroxyl groups must be halogenated first to allow the coupling of secondary amine branches, by adding concentrated $\mathrm{HBr}$ and heating at $160^{\circ} \mathrm{C}$. It is known that diethanolamine undergoes dehydration with sulfuric acid to form morpholine. ${ }^{13}$ In the presence of hydrobromic acid the compound $4 \mathrm{a}$ was formed when $2,2^{\prime}, 2^{\prime \prime}, 2^{\prime \prime \prime}-$ [1,4-phenylenebis(methylenenitrilo)]tetra-ethanol was used.

\section{CONCLUSION}

In this paper we reported the synthesis of two new dendrimers, having as the core 1,3,5-tris(bromo-methyl)benzene and 1,3,5-tris(bromomethyl)-2,4,6-trimethylbenzene, by derivatization with diethanolamine branches. The obtained compounds, with 4 or 6 hydroxyl terminal surface groups, show an increased water-solubility, in comparison with the parent molecules. 2,2',2", 2'" - [1,4 - phenylenebis(methylenenitrilo)]tetraethanol in presence of aqueous hydrogen bromide leaded to the formation of 4,4'-[1,4-phenylene-bis(methylene)]-dimorpholine.

Acknowledgements. The authors greatly acknowledge the financial support offered by Romanian UEFISCDI grant no. PN-II-ID-PCE-2011-3-0346.

\section{REFERENCES}

1. E. Buhleier, W. Wehner, and F. Vögtle, Synthesis 2 (1978) 155158.

2. Rangaraju, U. M. Kumar, K. Pragna, and A. Sandeep, PHARMANEST 4 (2013) 1197-1205.

3. P. A. Gauniva, A. Abhishek, and D. Sanjita, Asian J. Biochem. Pharm. Res. 2 (2011) 249-264.

4. J. L. Zurita, G. Repetto, A. Jos, A. del Peso, M. Salguero, M. López-Artíguez, D. Olano, and A. Cameán, Toxicol. In Vitro 19 (2005) 879-886.

5. M. Yar, N. Mushtaq, and S. Afzal, Russ. J. Org. Chem. 49 (2013) 949-967.

6. E. C. Constable, P. Harverson, and M. Oberholzer, Chem. Commun. 15 (1996) 1821-1822.

7. S. Nummelin, M. Skrifvars, and K. Rissanen, Polyester and ester functionalized dendrimer in: F. Vögtle (Ed), Dendrimers II: Arhitecture, Nanostructure and Supramolecular Chemistry, Springer Berlin Heidelberg, New York, 2000, p. 9.

8. E. H. H. Wong, O. Altintas, M. H. Stenzel, C. Barner-Kowollik, and T. Junkers, Chem. Commun. 47 (2011) 5491-5493.

9. H. Meier, M. Lehmann, and U. Kolb, Chem. Eur. J. 6 (2000) 2462-2469.

10. B. Wang, J. Fang, B. Li, H. You, D. Ma, Z. Hong, W. Li, and Z. Su, Thin Solid Films 516 (2008) 3123-3127.

11. R. Newkome, C. N. Moorefield, and F. Vögtle, Dendritic Molecules: Concepts, syntheses, perspectives, VCH Publishers Inc., New York, 1996, p. 60.

12. E. C. Constable and P. Harverson, Chem. Commun. 1 (1996) 33-34.

13. D. L. Cottle, A. E. Jeltsch, T. H. Stoudt, and D. R. Walters, J. Org. Chem. 11 (1946) 286-291.

14. V. Raman, J. Rai, M. Singh, and D. C. Parashar, Analyst 111 (1986) 189-191.

15. S.-K. Xiang, B. Zhang, L.-H. Zhang, Y. Cui, and N. Jiao, Chem. Commun. 47 (2011) 8097-8099.

16. M. M. Heravi, M. Zakeri, and N. Mohammadi, Chin. J. Chem. 29 (2011) 1163-1166.

17. A. Trabocchi, I. Stefanini, M. Morvillo, L. Ciofi, D. Cavalieri, and A. Guarna, Org. Biomol. Chem. 8 (2010) 5552-5557.

18. S. Tachikawa, M. Harada, and H. Maeno, Arch. Int. Pharmacodyn. Ther. 238 (1979) 81-95.

19. M. Kawalec, A. P. Dove, L. Mespouille, and P. Dubois, Polym. Chem. 4 (2013) 1260-1270.

20. H. Efe, M. Bicen, M. V. Kahraman, and N. Kayaman-Apohan, J. Braz. Chem. Soc. 24 (2013) 814-820.

21. M. F. A. Taleb, S. El-Sigeny, and M. El-Kemary, Macromol. Res. 20 (2012) 407-414.

22. A. Gescher and D. R. Newell, The Role of Pharmacokinetic and Metabolism Studies in Anticancer Drug Discovery and Development in: G. G. Gibson (Ed.), Progress in Drug Metabolism, Vol. 13, Taylor \& Francis Ltd., London, 1992, pp. 272-275.

23. N. Yao, D.-L. Liu, Y.-J. Li, Z.-S. Chen, Z. Shi, W.-M. Chen, Z. Yao, D.-M. Zhang, and W.-C. Ye, J. Cancer Res. Updates 3 (2014) 59-66.

24. S. Adimurthy and G. Joshi, Indian J. Chem. 49B (2010) 771775 .

25. C. S. Ho, C. W. K. Lam, M. H. M. Chan, R. C. K. Cheung, L. K. Law, L. C. W. Lit, K. F. Ng, M. W. M. Suen, and H. L. Tai, Clin. Biochem. Rev. 24(1) (2003) 3-12. 